\title{
Quantitative nuclear texture features analysis confirms WHO classification 2004 for lung carcinomas
}

\author{
Katharina Schmid ${ }^{1}$, Nina Angerstein ${ }^{2}$, Silvana Geleff ${ }^{1}$ and Andreas Gschwendtner ${ }^{2}$ \\ ${ }^{1}$ Department of Clinical Pathology, Medical University of Vienna, Vienna, Austria and ${ }^{2}$ Department of \\ Pathology, Clinicum Coburg, Coburg, Germany
}

\begin{abstract}
The purpose of this study was to discriminate the main subsets of lung carcinomas of the WHO classification of 2004 by nuclear chromatin texture feature analysis. Our collective comprised 56 typical and 19 atypical carcinoids, 37 small-cell carcinomas, 15 large-cell neuroendocrine carcinomas, 42 adenocarcinomas, and 26 squamous cell carcinomas. After Feulgen staining, cell nuclei were automatically measured using a highresolution image analyser (CytoSavant Oncometrics, Vancouver, BC, Canada). Texture features describing the granularity and the compactness of the nuclear chromatin were extracted for calculation of classification rules, which allowed the discrimination of different tumor groups. By applying the classification rule that described the granularity of the nuclear chromatin (defined by four different parameters) small-cell and non-small-cell lung carcinoma could correctly be discriminated in $93 \%$. No significant discrimination was possible between the different subtypes of large-cell carcinomas, including large-cell neuroendocrine carcinoma. When using compactness of chromatin (defined by four texture parameters) as a means of discrimination, carcinoids and non-small-cell lung carcinomas were correctly distinguished in $92 \%$. No significant discrimination between neuroendocrine tumors was achieved though. Our findings are in accordance with the new WHO classification of 2004: neuroendocrine tumors of the lung are now classified according only to their mitotic counts and presence of necrosis but not by their morphology; their discrimination by the means of nuclear image analysis is not sufficient and therefore not appropriate any longer.
\end{abstract}

Modern Pathology (2006) 19, 453-459. doi:10.1038/modpathol.3800541; published online 3 February 2006

Keywords: lung; carcinoma; WHO classification; nuclear texture features; high-resolution texture analysis

Nuclear texture feature analysis has repeatedly been used to discriminate between malignant tumors of the lung. Modern image analysing systems are easy to handle and are specifically designed for automatic, objective, and reproducible quantification of images of tissue specimens. It is well established that this method gives valuable additional information for better classification and prediction of human malignant tumors. ${ }^{1-4}$

Its value in classifying malignant lung tumors was confirmed by several authors:

First data for discriminating pulmonary carcinomas by texture parameters were published by Switzer et al in 1974. This study group measured the mean volume of tumor cells in different pulmonary

Correspondence: Dr K Schmid, MD, Department of Clinical Pathology, Medical University of Vienna, Waehringer Guertel 18-20, A-1090 Vienna, Austria.

E-mail: katharina.schmid@meduniwien.ac.at

Received 27 July 2005; revised 25 October 2005; accepted

5 November 2005; published online 3 February 2006 carcinomas types with different survival time. ${ }^{5}$ Modern morphological methods using digital image analysis were applied by Oberholzer et al in 1991, ${ }^{6}$ who investigated the differences between mesothelial cells, mesothelioma cells, and metastatic adenocarcinoma in pleural effusions. In 1992, Thunnissen $\mathrm{et} \mathrm{al}^{7}$ distinguished between small- cell lung carcinoma and non-small-cell lung carcinoma by quantitative nuclear texture analysis. This method was also useful in estimating the tumor grade of lung squamous cell carcinoma, which was shown by Ladekarl et al in $1995 .{ }^{8}$ Yokozaki et al ${ }^{9}$ differentiated between atypical adenomatous hyperplasia and adenocarcinoma of the lung by DNA histogram patterns and nuclear size, using an image cytometer. By means of high-resolution image analysis, Jütting et $a l^{10}$ evaluated the diagnosis and prognosis of neuroendocrine lung tumors in 1999.

Lung carcinomas comprise very different tumor types with different degrees of prognosis. The main tumor groups are adenocarcinoma, squamous cell carcinoma, small-cell lung carcinoma, which are 
highly malignant tumors. Large-cell neuroendocrine carcinoma is a small, relatively new described tumor subtype of large-cell tumors. ${ }^{11}$ Adenocarcinomas, squamous cell carcinomas, and large-cell neuroendocrine carcinomas are classified as non-smallcell lung carcinomas. Neuroendocrine lung tumors comprise typical and atypical carcinoid, small-cell lung carcinoma, and large-cell neuroendocrine carcinoma. Typical and atypical carcinoids are low and intermediate malignant tumors, respectively, and have a far better prognosis than all other lung carcinomas. Also in the recent World Health Organisation (WHO) classification of 2004, neuroendocrine tumors are still classified separately into the tumor groups of carcinoids, small-cell lung carcinomas and large-cell carcinomas. ${ }^{12}$

Owing to the significant differences in prognosis, objective methods for grading of neuroendocrine tumors are highly desirable. Grading on morphology alone-even in conjunction with immunohistochemistry or molecular techniques-has rendered confusing results. Therefore, nuclear texture feature analysis has repeatedly been introduced for classification of neuroendocrine tumors.

However, none of the studies published so far referred to the classification of lung tumors proposed by the WHO in 1999 and 2004. ${ }^{13,12}$ Compared to the former WHO classification of $1981,{ }^{14}$ some major changes have taken place:

1. The criteria for atypical carcinoids have been narrowed to better discriminate atypical carcinoids from other subtypes of neuroendocrine lung tumors.

2. The current WHO classification lacks subsets of small-cell lung carcinomas: no discrimination of oat cell carcinoma from small-cell lung carcinoma intermediate cell type or combined oat cell carcinoma is made any longer; all three subsets are now categorized as small-cell lung carcinoma only (because of their similar clinical course).

3. Large-cell neuroendocrine carcinoma has been added to the group of large-cell carcinomas.

In the present study, we evaluated the usefulness of high-resolution quantitative nuclear texture analysis for the classification of lung carcinomas with special emphasis on neuroendocrine carcinomas according to the proposed classification by the WHO in 2004. ${ }^{12}$ We also compared our results to those of previous studies applying former WHO classifications. ${ }^{10,7,15}$ To our knowledge, this is the first study applying nuclear texture analysis to the new WHO classification system.

\section{Materials and methods}

A total of 195 cases of resected lung tumors were retrieved from the archives of the Department of Clinical Pathology, Medical University of Vienna, collected during 1977-2002. The samples com- prised the main subsets of malignant lung tumors: 56 typical carcinoids, 19 atypical carcinoids, 37 small-cell lung carcinomas, 15 large-cell neuroendocrine carcinomas, 26 squamous cell carcinomas, and 42 adenocarcinomas. The histological specimens of all cases were re-examined by two of the authors (KS and SG) and classified according to the WHO recommendations, 2004. ${ }^{12}$ The subset of neuroendocrine lung tumors, comprising typical and atypical carcinoid, small-cell lung carcinoma, and large-cell neuroendocrine carcinoma, was reassessed based on the histological criteria proposed by Travis et al. ${ }^{11,16}$ Adeno- and squamous cell carcinomas were classified depending on the presence of mucin and keratinization and/or intercellular bridges, respectively.

It is now well accepted that typical carcinoid is a well-differentiated tumor with neuroendocrine histomorphology; it shows up to one mitotic count per 10 high-power fields, lacks necrosis, and corresponds to tumor grade G1. Atypical carcinoid is characterized by small foci of necrosis and/or mild mitotic activity (2-10 mitoses per 10 high-power fields) and graded G2. In small-cell lung carcinoma and large-cell neuroendocrine carcinoma, prominent necrosis and high mitotic activity are evident, and both are classified as G3 tumors.

In all our cases, neuroendocrine differentiation was confirmed by immunohistochemical staining for chromogranin A and/or N-CAM according to a standard protocol. ${ }^{17,18}$

\section{Tissue Processing for Image Analysis}

For measurement of cell nuclei, single-cell preparations were used. From each case, the most representative tissue block, in which the surrounding normal tissue could be clearly separated from the tumor, was selected. The tumor area was delineated on the corresponding H\&E-stained paraffin section and cut off the block before disintegration. This ensured that in the disintegrated material, mainly tumor cells were present. Two 50- $\mu$ m-thick sections were cut, and cell nuclei were extracted following the protocol of Mikuz et al. ${ }^{19}$ Then, the nuclei were attached to a glass slide and were stained according to the recommendations of the Armed Forces Institute of Pathology laboratory manual, using the Feulgen Azur A staining protocol. ${ }^{20}$ For quality control of the staining, single-cell preparations of rat liver tissue were included in each staining batch. A computer-controlled staining machine with constant temperature for the staining batches was used (adapted auto slide stainer by micron, Zeiss, Germany).

\section{Image Analysis}

The slides were measured using a CytoSavant image analyser (Oncometrics Inc., Vancouver, BC, Canada). 
This device consisted of a Nikon Optiphot 2 microscope equipped with a $20^{*}$ plan Apo objective (numerical aperture 0.75). This low magnification power has a concomitantly large focal depth, so that virtually all the nuclei are in focus at this magnification. A high-resolution digital camera with a scientific-grade charged coupled device (CCD) (Microimager 1400, Xillix Corp., Vancouver, BC, Canada) was used in combination with a Matrox 1280 image-processing board (Matrox Corp, Dorval, QC, Canada) and an IBM-compatible PC. To enhance contrast, a 610-nm narrow-band bypass filter was used. Acquisition of the cells was controlled by ACQUIRE Software (Oncometrics Inc.). This software employs an automated focus algorithm ensuring that all nuclear images are collected in exact focus. It also employs algorithms for automated detection of the nuclear boundaries along the highest gradient between the nuclear stain and unstained background; this defines the nuclear boundary in a precise, objective, and reproducible way. ${ }^{21}$

At least 20000 objects per case were measured automatically. From these measurements, only epithelial cell nuclei were extracted after having cleaned the measurements for cell clusters and separated the residual cells into different histomorphological groups using integrated cell separation software (TANC classification tree).

For quality control, all epithelial cell nuclei were then reviewed on screen interactively by three experienced observers (AG, KS, and NA), using a cell gallery. Finally, at least 1000 manually selected nuclei were used for each case for further processing. For normalization of the DNA content of nuclei, at least 100 well-preserved fibroblasts were used as an internal reference. To ensure that only epithelial cells showing the same DNA content were compared, a mathematical algorithm was applied to the cells after review, filtering out all but strictly diploid cells.

\section{Calculation of Nuclear Characteristics (Texture Features)}

From each nuclear image, 114 nuclear descriptors were extracted. The features calculated have been described in previous studies. ${ }^{22}$

\section{Statistical Evaluation}

For deriving a classifier for the different tumor entities, the measured cases were grouped into two classes: typical carcinoid, atypical carcinoid, and small-cell carcinoma as well as adenocarcinoma and squamous cell carcinoma (the second group comprised the major subtypes of large-cell carcinomas). To generate a classification rule for discrimination between the different tumor entities, the mean values, maximum, minimum, and variances for all 114 features were computed for each case. The mean and standard deviation (s.d.) of each of the features were used to create the classification rule using stepwise linear discriminant function analysis (Classify Software, Oncometrics Inc.). To avoid overtraining, a maximum of four features was allowed to create a discriminant function with respect to the number of cases included in the study. ${ }^{23}$

The discriminant function derived from the tumor classes described above was then applied to each single tumor entity. The classifying power of this discriminant function was expressed by the percentage of overall correctly classified cases for each tumor class (compare cross tables in the 'Results' section). For all tests, a value of $\geq 60.0 \%$ was considered significant.

\section{Results}

\section{Demographics and Clinical Data}

The study group comprised 112 male and 85 female subjects; the mean age of patients at the time of surgery was $60 \pm 13$ years. The result of pathological tumor grading was 67 cases G1, 58 cases G2, and 70 cases G3, and pathological tumor staging revealed 112 pT1, 63 pT2, 3 pT3, and 17 pT4 tumors, respectively (for more details, see Table 1).

\section{Discrimination between Typical/Atypical Carcinoid, Adeno-/Sqamous Cell Carcinoma, Large-Cell Neuroendocrine Carcinoma and Small-Cell Lung Carcinoma by Parameters Describing the Compactness of the Chromatin}

None of all evaluated texture parameters allowed discrimination between typical and atypical carcinoid as well as adenocarcinoma and squamous cell carcinoma. Therefore, these groups have been summarized for further evaluation: typical/atypical carcinoid and adeno-/sqamous cell carinoma.

We established a classification rule comprising four different texture parameters, which all describe the compactness of the chromatin: mean harmony, s.d. of gray level, s.d. of run length, and s.d. of run percent. Applying this classificator it was possible to discriminate between typical/atypical carcinoid and large-cell neuroendocrine carcinoma as well as typical/atypical carcinoid and adeno-/squamous cell carinoma, respectively. We found an overall discrimination of $93 \%$ and $92 \%$, respectively. Typical/atypical carcinoid was correctly classified in $93 \%$ and $95 \%$ of cases, respectively, large-cell neuroendocrine carcinoma in 93\%, and adeno-/ squamous cell carcinoma in $90 \%$ of cases, respectively (see also Tables 2 and 3).

Applying this classification rule to typical/atypcial carcinoid vs small-cell lung carcinoma, we found a significantly lower overall discrimination value of $86 \%$ (correctly classified cases: typical/ 
Table 1 Cross table of tumor type and number of cases, mean age, sex of patients, tumor grade, and tumor stage $(n=195)$

\begin{tabular}{|c|c|c|c|c|c|c|c|c|c|c|c|}
\hline \multirow[t]{2}{*}{ Tumor type } & \multirow{2}{*}{$\begin{array}{l}\text { Number } \\
\text { of cases }\end{array}$} & \multirow{2}{*}{$\begin{array}{c}\text { Mean } \\
\text { age }\end{array}$} & \multicolumn{2}{|c|}{ Sex of patients } & \multicolumn{3}{|c|}{ Tumor grade } & \multicolumn{4}{|c|}{ Tumor stage } \\
\hline & & & Male & Female & G1 & G2 & G3 & $p T 1$ & pT2 & $p T 3$ & $p T 4$ \\
\hline Typical carcinoids & 56 & $54 \pm 17$ & 22 & 34 & 56 & - & - & 47 & 8 & 0 & 1 \\
\hline Atypical carcinoids & 19 & $56 \pm 13$ & 9 & 10 & - & 19 & - & 8 & 5 & 1 & 5 \\
\hline Small-cell lung carcioma & 37 & $63 \pm 12$ & 23 & 14 & - & - & 37 & 18 & 14 & 1 & 4 \\
\hline Large-cell neuroendocrine carcinoma & 15 & $62 \pm 8$ & 13 & 2 & - & - & 15 & 7 & 8 & 0 & 0 \\
\hline Adenocarcinoma & 42 & $63 \pm 10$ & 25 & 17 & 11 & 20 & 11 & 22 & 13 & 1 & 6 \\
\hline Squamous cell carcinoma & 26 & $66 \pm 6$ & 20 & 6 & 0 & 19 & 7 & 10 & 15 & 0 & 1 \\
\hline Total & 195 & $60 \pm 13$ & 112 & 83 & 67 & 58 & 70 & 112 & 63 & 3 & 17 \\
\hline
\end{tabular}

Table 2 Cross table for discrimination of typical/atypical carcinoid versus large cell neuroendocrine carcinoma applying four texture parameters describing the chromatin compactness $(n=90)$

\begin{tabular}{lcccc}
\hline Tumor type & $\begin{array}{c}\text { Number } \\
\text { of cases }\end{array}$ & $\begin{array}{c}\text { Cases classified as } \\
\text { typical or atypical } \\
\text { carcinoid }\end{array}$ & $\begin{array}{c}\text { Cases classified as } \\
\text { large cell neuroendocrine } \\
\text { carcinoma }\end{array}$ & $\begin{array}{c}\text { Correctly classified } \\
\text { cases (\%) }\end{array}$ \\
\hline $\begin{array}{l}\text { Typical and atypical carcinoid } \\
\text { Large-cell neuroendocrine carcinoma }\end{array}$ & 75 & 70 & 5 & 93 \\
Total & 90 & 15 & 14 & 93 \\
\end{tabular}

Table 3 Cross table for discrimination of typical/atypical carcinoid vs adeno-/squamous cell carcinoma applying four texture parameters describing the chromatin compactness $(n=143)$

\begin{tabular}{lcccc}
\hline Tumor type & $\begin{array}{c}\text { Number } \\
\text { of cases }\end{array}$ & $\begin{array}{c}\text { Cases classified as } \\
\text { typical or atypical } \\
\text { carcinoid }\end{array}$ & $\begin{array}{c}\text { Cases classified as } \\
\text { adeno- or squamous } \\
\text { cell carcinoma }\end{array}$ & $\begin{array}{c}\text { Correctly classified } \\
\text { cases (\%) }\end{array}$ \\
\hline $\begin{array}{l}\text { Typical and atypical carcinoid } \\
\text { Adeno- and squamous cell carcinoma }\end{array}$ & 75 & 71 & 4 & 95 \\
Total & 68 & 7 & 61 & 90 \\
\hline
\end{tabular}

atypical carinoid 88\%, small-cell lung carcinoma 81\%; compare Table 4).

By this classificatory, small-cell lung carcinoma could hardly be discriminated from large-cell neuroendocrine carcinoma (overall discrimination value $72 \%$ ), and could not be discriminated from adeno-/ squamous cell carcinoma (overall discrimination value $<60 \%$ ).

\section{Discrimination between Small-Cell Lung Carcinoma, Adenocarinoma, Squmous Cell Carcinoma, and Large-Cell Neuroendocrine Carcinoma by Parameters Describing the Granularity of the Chromatin}

As the first mentioned classification rule could not reliably discriminate between small-cell and nonsmall-cell lung carinoma, we developed another classification rule comprising four texture parameters mainly describing the chromatin granularity: mean high DNA compactness, s.d. of high DNA amount, s.d. of high average density, and s.d. of density light spot.

Applying this second classificatory, we found an overall discrimination of $93 \%$ between small-cell lung carinoma and adeno-/squamous cell carinoma; $92 \%$ of the small-cell lung carcinomas and $94 \%$ of the adeno-/squamous cell carcinomas were correctly classified (see also Table 5).

Application of this classification rule for discrimination between small-cell lung carcinoma and largecell neuroendocrine carcinoma as well as adeno-/ squamous cell carcinoma and large-cell neuroendocrine carcinoma, respectively, revealed a significantly lower overall discrimination value of $73 \%$ and $87 \%$ (compare Table 6 and 7 ). 
Table 4 Cross table for discrimination of typical/atypical carcinoid versus small cell lung carcinoma applying 4 texture parameters describing the chromatin compactness $(n=112)$

\begin{tabular}{lcccc}
\hline Tumor type & $\begin{array}{c}\text { Number } \\
\text { of cases }\end{array}$ & $\begin{array}{c}\text { Cases classified as } \\
\text { typical or atypical } \\
\text { carcinoid }\end{array}$ & $\begin{array}{c}\text { Cases classified as } \\
\text { small cell lung } \\
\text { carcinoma }\end{array}$ & $\begin{array}{c}\text { Correctly classified } \\
\text { cases (\%) }\end{array}$ \\
\hline $\begin{array}{l}\text { Typical and atypical carcinoid } \\
\text { Small-cell lung carcinoma }\end{array}$ & 75 & 66 & 9 & 88 \\
Total & 37 & 7 & 30 & 81 \\
\hline
\end{tabular}

Table 5 Cross table for discrimination of small-cell lung carcinoma vs adeno-/squamous cell carcinoma applying four texture parameters describing mainly the chromatin granularity $(n=105)$

\begin{tabular}{lcccc}
\hline Tumor type & $\begin{array}{c}\text { Number } \\
\text { of cases }\end{array}$ & $\begin{array}{c}\text { Cases classified as } \\
\text { small-cell lung } \\
\text { carcinoma }\end{array}$ & $\begin{array}{c}\text { Cases classified as } \\
\text { adeno- or squamous cell } \\
\text { carcinoma }\end{array}$ & $\begin{array}{c}\text { Correctly classified } \\
\text { cases (\%) }\end{array}$ \\
\hline Small-cell lung carcinoma & 37 & 34 & 3 & 92 \\
Adeno- and squamous cell carcinoma & 68 & 4 & 64 & 94 \\
Total & 105 & 38 & 67 & 93 \\
\hline
\end{tabular}

Table 6 Cross table for discrimination of small-cell lung carcinoma vs large-cell neuroendocrine carcinoma applying four texture parameters describing mainly the chromatin granularity $(n=52)$

\begin{tabular}{lcccc}
\hline Tumor type & $\begin{array}{c}\text { Number } \\
\text { of cases }\end{array}$ & $\begin{array}{c}\text { Cases classified } \\
\text { as small-cell lung } \\
\text { carcinoma }\end{array}$ & $\begin{array}{c}\text { Cases classified as } \\
\text { large-cell neuroendocrine } \\
\text { carcinoma }\end{array}$ & $\begin{array}{c}\text { Correctly classified } \\
\text { cases (\%) }\end{array}$ \\
\hline Small-cell lung carcinoma & 37 & 29 & 8 & 78 \\
Large-cell neuroendocrine carcinoma & 15 & 6 & 9 & 60 \\
Total & 52 & 35 & 17 & 87 \\
\hline
\end{tabular}

Table 7 Cross table for discrimination of large-cell neuroendocrine carcinoma vs adeno-/squamous cell carcinoma applying four texture parameters describing mainly the chromatin granularity $(n=83)$

\begin{tabular}{lcccc}
\hline Tumor type & $\begin{array}{c}\text { Number } \\
\text { of cases }\end{array}$ & $\begin{array}{c}\text { Cases classified as } \\
\text { large-cell neuroendocrine } \\
\text { carcinoma }\end{array}$ & $\begin{array}{c}\text { Cases classified as } \\
\text { adeno- or squamous cell } \\
\text { carcinoma }\end{array}$ & $\begin{array}{c}\text { Correctly classified } \\
\text { cases (\%) }\end{array}$ \\
\hline Large-cell neuroendocrine carcinoma & 15 & 10 & 5 & 67 \\
Adeno- and squamous cell carcinoma & 68 & 6 & 62 & 91 \\
Total & 83 & 16 & 67 & 86 \\
\hline
\end{tabular}

Typical/atypical carcinoid could not be discriminated from small-cell lung carinoma, adeno-/squamous cell carcinoma, and large-cell neuroendocrine carcinoma, by applying this classification rule (all overall discrimination values $<60 \%$ ).

\section{Discussion}

This is the first study in which image analysis data are correlated with the new WHO classification 2004 for lung tumors, recently introduced by Travis et al. ${ }^{12}$ Moreover, the techniques and statistical evaluation used in our study are more complex than in any used previously. Our results are highly reproducible because state of the art automated techniques allowed us to analyse a higher number of cases per tumor group and to measure a higher number of cell nuclei per case. We incorporated only four features in each of the two selected classifiers (chromatin granularity and chromatin compactness), which ensured that no overtraining of the classifier could take place. 
In our collective, the cell nuclei of typical and atypical carcinoid could not be discriminated by any of over a 100 incorporated texture features parameters (overall discrimination value $<60 \%$ ), which confirms the findings of the previous study of Jütting et $a l^{12}$ and is in accordance with the WHO 2004 classification. ${ }^{12}$ Those two tumor entities are both characterized by the same growth patterns and cytological features. The number of mitoses and presence of punctuate necrosis are the only criteria to separate atypical carcinoid from typical carcinoid. Furthermore, no morphological parameters like nuclear size or chromatin features are incorporated in the WHO histological classification any longer.

By looking for a classifier to discriminate between carcinoids and other tumor subsets, we established a classification rule comprising four texture parameters features, which describe the compactness of the nuclear chromatin. By applying this classification rule, typical/atypical carcinoid was easily discriminated from non-small-cell lung carcinoma, including large-cell neuroendocrine carcinoma. An overall discrimination of $92 \%$ (adeno-/squamous cell carcinoma) and 93\% (large-cell neuroendocrine carcinoma) was reached, respectively. Jütting et $a l^{10}$ presented similar findings in 1999.

In clear contrast to the study of Jütting et $a l,{ }^{10}$ the neuroendocrine tumor groups typical/atypical carcinoid and small-cell lung carcinoma could not be well distinguished from each other by applying the above-mentioned classification rule (overall discrimination value $86 \%$ ).

We believe that this is due to the fact that subsets of small-cell lung carcinoma (oat cell carcinoma and small-cell lung carcinoma intermediate cell type) were eliminated from the current WHO classification because of their similar clinical course. Therefore, small-cell lung carcinoma became a morphologically heterogeneous tumor group. This unification of previously distinct subsets of smallcell lung carcinoma could also explain the unexpected finding that small-cell lung carcinoma and large-cell neuroendocrine carcinoma could not be well discriminated by the means of nuclear image analysis; only an overall discrimination value of $73 \%$ was reached. For this reason the classification rule used for discriminating small-cell lung carcinoma and large-cell neuroendocrine carcinoma mainly described differences of chromatin granularity in the cell nuclei and comprised mean high DNA compactness, s.d. of high DNA amount, s.d. of high average density, and s.d. of density light spot.

Again, our findings reflect the new WHO classification, in which the distinction between the subsets of neuroendocrine lung tumors is mainly achieved by assessment of mitotic counts and presence of necrosis; only the distinction of smallcell lung carcinoma and large-cell neuroendocrine carcinoma is defined by morphologic criteria as cell size, amount of cytoplasm, and presence or absence of nucleoli; ${ }^{12}$ but these criteria are sometimes difficult to apply as small-cell lung carcinoma may show up with varying degrees of cell size and sometimes in part present with nucleoli. Moreover, the nuclear chromatin of large-cell neuroendocrine tumor cells ranges from vesicular to finely granular and often resembles that of small-cell lung carcinoma tumor cells. ${ }^{11}$

Based on our measurements, no discrimination between the subsets of tumor groups of non-smallcell lung carcinoma (comprising adenocarcinoma, squamous cell carcinoma, and large-cell neuroendocrine carcinoma), no matter which texture parameters got applied, was possible (all overall discrimination values $<60 \%$ ). Similar data were found in previous studies. ${ }^{7,15}$ This observation can be explained by the great histological heterogeneity of non-small-cell lung carcinomas; variations in appearance and differentiation in different microscopic fields and histological sections are common. It is now well known that almost $50 \%$ of non-smallcell lung carcinomas exhibit more than one of the major histological subtypes and the extent of histological sampling influences its classification. In particular, histological subclassification of adenocarcinoma is fraught with difficulty since these tumors are highly heterogeneous. This is reflected in the current WHO classification where it is recognized that most adenocarcinomas correspond to the mixed subtype. ${ }^{12}$

In addition, little is known about the relatively small group of large-cell neuroendocrine carcinoma (1-2\% of all malignant lung tumors), which is a relatively new tumor entity (described at the end of 1980s). Still no clear therapy guidelines exist for the treatment of patients suffering from large-cell neuroendocrine carinoma.

Its histological classification is tricky and demarcation from small-cell lung carcinoma often difficult: small-cell lung carcinoma as well as large-cell neuroendocrine carcinoma show neuroendocrine growth pattern, prominent necrosis, and high mitotic rate; as mentioned above, they are only differentiated by cell size, amount of cytoplasm, and the presence and size or absence of nucleoli.

In the current WHO classification, large-cell neuroendocrine carcinoma is still included in the group of large-cell lung carcinoma. ${ }^{12}$

This is in accordance with our findings, in which large-cell neuroendocrine carcinoma could not be well discriminated from other subsets of non-smallcell lung carcinomas by above-mentioned classificator describing mainly the granularity of the chromatin (overall discrimination value $87 \%$ ).

Comparing small-cell lung carcinoma to the group of adeno-/squamous cell carcinoma, the same classification rule allowed an overall discrimination of $93 \%$. This finding corresponds well to the different histological criteria used both in the former and current WHO classifications for those tumors: tumor cells of small-cell lung carcinomas are small 
(usually less than the size of three small resting lymphocytes) and their nuclear chromatin is finely granular and nucleoli are absent or inconspicuous. In contrast, the tumor cells and nuclei of adenocarinoma and squamous cell carcinoma are larger, their chromatin is coarse or vesicular, and nucleoli are prominent. $^{12,13}$ Thunnissen et $a l^{7}$ reported similar data in 1992.

We conclude that modern high-resolution image analysis is still a potent tool to support the differentiation of small-cell carcinoma as well as carcinoids from adenocarcinoma, squamous cell carcinoma, and large-cell neuroendocrine carcinoma. However, in contrast to previous published data, ${ }^{7,10}$ which referred to past WHO classifications, ${ }^{13,14}$ it is no longer adequate to discriminate neuroendocrine lung tumors (typical and atypical carcinoid, small-cell lung carcinoma, and large-cell neuroendocrine carcinoma) by means of quantitative nuclear texture features analysis.

\section{References}

1 Neher A, Öfner G, Appenroth E, et al. High-resolution image cytometry on smears of normal oral mucosa: a possible approach for the early detection of laryngopharyngeal cancers. Head Neck 2004;26:694-700.

2 Montironi R, Thompson D, Scarpelli M, et al. Karyometry detects subvisual differences in chromatin organization state between cribriform and flat highgrade prostatic intraepithelial neoplasia. Mod Pathol 2004;17:928-937.

3 Scarpelli M, Baccarini MG, Colanzi P, et al. Chromatin texture analysis of adrenal gland adenomas, including incidentalomas, and adjacent normal-appearing cortical tissue. Anal Quant Cytol Histol 2000;22:235-243.

4 Gschwendtner A, Hoffmann-Weltin Y, Mikuz G, et al. Quantitative assessment of bladder cancer by nuclear texture analysis using automated high-resolution image cytometry. Mod Pathol 1999;12:806-813.

5 Switzer P, Gerstl B, Greenspoon J. Karyometry in the estimation of nuclear population in pulmonary carcinomas. J Natl Cancer Inst 1974;52:1699-1704.

6 Oberholzer M, Ettlin R, Christen H, et al. The significance of morphometric methods in cytologic diagnostics: differentiation between mesothelial cells, mesothelioma cells and metastatic adenocarcinoma cells in pleural effusions with special emphasis on chromatin texture. Anal Cell Pathol 1991;3:25-42.

7 Thunnissen FBJM, Diegenbach PC, van Hattum AH, et al. Further evaluation of quantitative nuclear image features for classification of lung carcinomas. Pathol Res Pract 1992;188:531-535.

8 Ladekarl M, Boek-Hansen T, Henrik-Nielsen R, et al. Objective malignancy grading of squamous cell carcinoma of the lung: stereologic estimates of mean nuclear size are of prognostic value, independent of clinical stage of disease. Cancer 1995;76:797-802.
9 Yokozaki M, Kodama T, Yokose T, et al. Differentiation of atypical adenomatous hyperplasia and adenocarcinoma of the lung by use of DNA ploidy and morphometric analysis. Mod Pathol 1996;9:1156-1164.

10 Jütting U, Gais P, Rodenacker K, et al. Diagnosis and prognosis of neuroendocrine tumors of the lung by means of high resolution image analysis. Anal Cell Pathol 1999;18:109-119.

11 Travis WD, Linnoila RI, Tsokos MG, et al. Neuroendocrine tumors of the lung with proposed criteria for large-cell neuroendocrine carcinoma. An ultrastructural, immunohistochemical, and flow cytometric study of 35 cases. Am J Surg Pathol 1991;15:529-553.

12 Travis WD, Brambilla E, Müller-Hermelink HK, et al (eds). World Health Organisation Classification of Tumors. Pathology and Genetics of Tumors of the Lung, Pleura, Thymus and Heart, 4th edn. WHO: Geneva, 2004, p 1.

13 Travis WD, Colby TV, Corrin B, et al (eds). Histological Typing of Lung and Pleural Tumours, 3rd edn. WHO: Geneva, 1999, p 1.

14 Kreyberg L, Liebow AA, Uehlinger EA, (eds). Histological Typing of Lung Tumours, 2nd edn. WHO: Geneva, 1981, p 1.

15 Thunnissen EB, Diegenbach PC. Classification of lung carcinoma by means of digital nuclear image analysis. Anal Quant Cytol Histol 1986;8:301-304.

16 Travis WD, Rush W, Flieder DB, et al. Survival analysis of 200 pulmonary neuroendocrine tumors with clarification of criteria for atypical carcinoid and its separation from typical carcinoid. Am J Surg Pathol 1998;22:934-944.

17 Lantuejoul S, Moro D, Michalides RJ, et al. Neural cell adhesion molecules (NCAM) and NCAM-PSA expression in neuroendocrine lung tumors. Am J Surg Pathol 1998;22:1267-1276.

18 Wilson BS, Lloyd RV. Detection of chromogranin in neuroendocrine cells with a monoclonal antibody. Am J Pathol 1984;115:458-468.

19 Mikuz G, Hofstaedter F, Delgado R. Extraction of cells from paraffin-embedded tissue sections for single cell DNA cytophotometry. Anal Quant Cytol Histol 1985;7: 343-346.

20 Mikel UV. Quantitative staining techniques for image cytometry. In: Mikel UV (ed). Advanced Laboratory Methods in Histology and Pathology. Armed Forces Institute of Pathology: Washington DC, 1994, pp 131-159.

21 Garner DM, Harrison A, MacAulay C, et al. CytoSavant and its use in automated screening of cervical smears. In: Wied GL, Bartels PH, Rosenthal DL, Schnck $\mathrm{U}$ (eds). Compendium on the Computerized Cytology and Histology Laboratory. Tutorials of Cytology: Chicago, 1994, pp 346-352.

22 Mairinger T, Mikuz G, Gschwendtner A. Nuclear chromatin texture analysis of nonmalignant tissue can detect adjacent prostatic adenocarinoma. Prostate 1999;41:12-19.

23 Schulerud H, Kristensen GB, Liestol K, et al. A review of caveats in statistical nuclear image analysis. Anal Cell Pathol 1998;16:63-82. 